Distribution of hospitals through Baghdad province using Geographic Information System

\author{
Dr. Zehraa Najim \\ Assist.prof. physics /college of science \\ /university of Baghdad. \\ Zehraa.najim@sc.uobaghdad.edu.iq
}

DOI: $\underline{\text { 10.31973/aj.v1i137.1375 }}$

\begin{abstract}
:
This research study the distribution of hospitals in the province of Baghdad Using geographic information system to focus on the shortage of hospitals in specific regions in comparison with other regions. In the distribution of hospitals in the city of Baghdad using Arc GIS program, we noticed that there is a shortage in the number of hospitals in the city of Kadhimiya, Sadr city and other areas compared to the increase in the population in these areas. There are enough hospitals in the area of Andalus square.
\end{abstract}

Keywords: Arc-GiS, hospitals, province of Baghdad, al khadimiyah, sadr city

\title{
Introduction
}

\section{Geographic Information Systems}

It is a computer-based system that collects, maintains, stores, analyzes, outputs and distributes spatial data and Information. These systems collect, input, process, analyze, display and produce spatial and descriptive information for specific objectives, and assist planning and decision-making in agriculture, urban planning and housing expansion. The infrastructure of any city by creating the so-called Layers, we can enter the geographical information (maps, aerial photographs, satellite images), descriptors (names, tables), process them (fix them from error), store them, retrieve them, query them, analyze them Yale spatial and statistical, and displayed on a computer screen or on paper in the form of maps, reports, charts and graphics or through the website (1).

At the local or individual level, the problem of finding the best location for a branch of a new establishment from a chain of commercial branches, finding the best soil type suitable for 


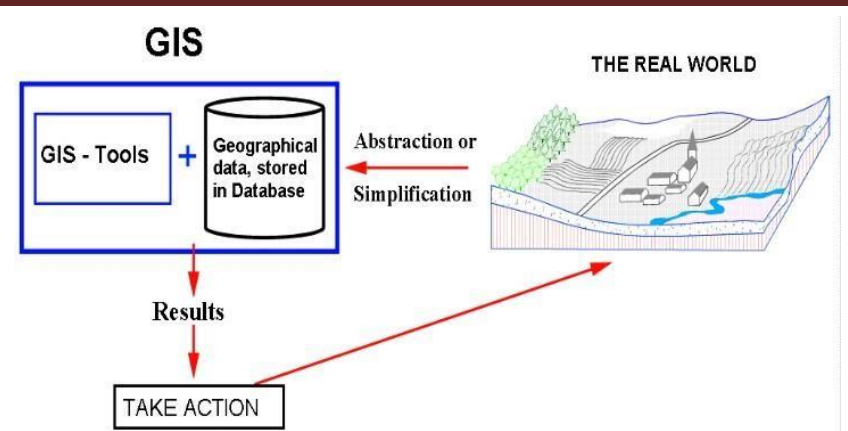

(Figure 1) Linking spatial and descriptive data in one database within geographic information systems contributes to supporting different decision-making. planting a new crop or determining the best route on the road network for a fire truck or ambulance (1).

\section{Benefits of GIS}

There are many benefits to GIS that can be summarized in the following (2).

1. Reduction of production time and improve accuracy: For example, if the production of a map needs more than one day we find now and using the computer can be accomplished in less than an hour. Using the computer, I said many of the errors that were produced by man in the production of maps due to weather factors, fatigue and nerves, and the psychological situation and all this led to improved accuracy.

2. Reduction of employment: In the past, cartographic laboratories were labor intensive because of the need for them in drawing, line, and coloring, but now one factor and the use of geographic information systems can replace three workers than they were in the past, from reducing indirect cost (1).

3. Cost reduction: Given the two benefits mentioned above, we find that they reduce cost and according to economic theories, time and time of production and labor means financial gain. Here, it should be noted that the initial cost of establishing GIS can be high, in some cases, the value of the dollar may not be directly material, but may be in the form of human development and human development. Information management also helps to increase efficiency and increase the cost/benefit ratio (3)

\section{The need for GIS}

The need for geographic information systems in different fields and disciplines such as urban planning, environmental protection, land use, facilities management, etc. has evolved due to its ability to organize and analyze geographic information, which has the following capabilities (4):

1. The possibility of linking spatial and descriptive data.

2. Ability to handle multiple layers of data simultaneously.

3. Analytical capacity. 
4. Contribute to support decision-making.

\section{Components of Geographic Information Systems}

Geographic Information Systems (GIS) are made up of basic elements (5):

1-spatial and descriptive information

2-computers

3-application programs

4-human resources (lapor force)

5-the methods used for spatial analysis

6-means

\section{How the GIS works}

The Geographic Information System (GIS) stores information about the world in the form of a set of geographically linked "thematic maps" in a simple, yet very powerful, scientific form that has proved important in solving many of the problems of the outside world, ranging from simple applications related to problems Daily life and even complex applications that may reach the work of a model for the cycle of the cosmic ocean (7)

\section{Models Raster \& Vector}

Geographic information systems operate on two basic models: Vector \& Raster. In Vector, information about points, lines, and polygons is represented by a code and stored in a set of $\mathrm{x}, \mathrm{y}$ arrangements (8). The description of a point such as a well can be described as a single point represented by single coordinates (x, y).

The description of lines such as river streets can be stored as a set of point arrangements. For polygons such as residential areas and river ports, the vector model is used to describe fixed objects but is not useful in describing the ever-changing objects such as the soil type, the environmental condition of a particular area or the shape of the beach in a given period of time. The Raster model was used for this type of object Permanent change in shape or characteristics, and a picture (Raster) consists of a set of Layer being scanned map or image (9).
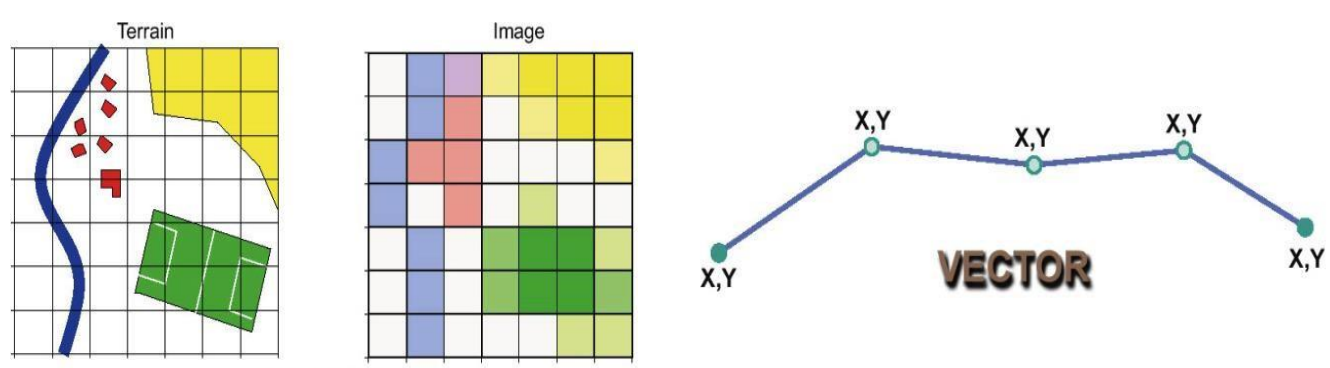

\section{RASTER}

(Figure 2) shows the difference between the use of both Raster and Vector to represent things in nature. 
Both Raster and Vector are used to store geographic information and each has advantages and disadvantages as shown in figure 5. The modern geographic information system can handle both models, and Raster data files can be integrated into the computer but are generally less detailed and less visual in comparison to the Vector data files that generally appear in the traditional map image (10), Vector "can be grouped and seen in a dot or in the form of lines or spaces and as an example of the model data contained in vector files can be the boundaries of subdivisions and subdivisions for example," the following is a comparison between the specifications of models (9):

\begin{tabular}{|l||l||}
\hline Data (Vector) & (Raster) Data \\
\hline High spatial accuracy & Decrease in spatial precision \\
\hline Small files (less storage) & Large files (images) \\
\hline $\begin{array}{l}\text { It is difficult to analyze as it is } \\
\text { stored in a large-dimensional } \\
\text { list }\end{array}$ & $\begin{array}{l}\text { Easy analysis can also prepare a } \\
\text { complex analysis }\end{array}$ \\
\hline $\begin{array}{l}\text { Quick analysis and display } \\
\text { speed }\end{array}$ & Slow analysis and slow display \\
\hline $\begin{array}{l}\text { Easy to understand for a wide } \\
\text { range of people }\end{array}$ & $\begin{array}{l}\text { It is difficult to understand the } \\
\text { public sector of people }\end{array}$ \\
\hline $\begin{array}{l}\text { Requires high technology and } \\
\text { expensive systems }\end{array}$ & $\begin{array}{l}\text { Requires low technology and } \\
\text { systems not high price }\end{array}$ \\
\hline $\begin{array}{l}\text { It is used in applications with } \\
\text { fixed conditions such as urban } \\
\text { planning, location of services } \\
\text { and facilities, and crisis } \\
\text { management. }\end{array}$ & $\begin{array}{l}\text { It is aped in applications of } \\
\text { permanent objects, such as } \\
\text { environmental characteristics, } \\
\text { climate, plant species, changes in } \\
\text { terrain, etc. }\end{array}$ \\
\hline
\end{tabular}

Table (1): comparison between models

\section{Steps to build a geographic information system}

The purpose of building geographic databases is to simulate the reality by building a model of its real world objects, in addition to the reciprocal relations between these components, giving each of these components its characteristic characteristics in nature, in order to simulate reality in all its details, Which maximizes the use of geographic information systems, and the process of establishing a geographic information system that goes through many stages and can be trapped in the following points (10):

1-Date collection

2-Input 
3-Data manipulation

4-Data integration

5-Data projection and scaling completeness

\section{Definition of Database:}

It is the amount of data used and placed in an organized manner within the computer for use in the extraction of information such as: images, maps, and tables, that is, the data set linked together, and stored in the computer in an orderly manner, in which all data is stored on a given object, whatever the size or type of data It is the place where data is stored and collected by a specific system. This data collects a common relationship and stored data is stored in the most appropriate way to be used and converted to information when needed (8)

\section{DATA MANAGEMENT}

For small GIS projects, it may be sufficient to store geographic information in ordinary files. However, when the data size becomes large and the number of users management software (DBMS) to help store, organize and manage date (9).

GIS APPLICATIONS (11)

1-Urban planning

2-In the field of roads

3 -In the area of crime rates

4-In the distribution of groundwater or rainfall rate

5-In the field of geological studies

\section{Objective of the Study}

Highlight the distribution of hospitals within the city of

Baghdad and of the knowledge shortage in distribution

In the distribution of hospitals in the city of Baghdad using Arc GIS program, we noticed that there is a shortage in the number of hospitals in the city of kadhimiya, sadr city and other areas compared to the increase in the population in these areas. There are enough hospitals in the area of Andalus square.

\section{Research methodology}

There are multiple approaches used in the scientific study and this study will depend on the following approaches

1-Descriptive approach: This method has been used to learn about the characteristics of hospitals province and find the relationship between human factors and the nature of the place

2-Historical curriculum: To study the development and change in the number of hospitals over the years covered by the study

3-The applied approach that will be based on GIS program ArcGis10.1 in the representation of the stages of the study, and the process of mapping $\varpi$ Analytical approach: Where the input data will 
be analyzed and determine the extent of the problem, and identify the direct and indirect causes affecting. The stages will be applied as follows:

- Determining the number of hospitals

- Draw digital maps for Salah al-Din province using GIS and drop the coordinates of schools distributed to all regions

- Set up a spatial database by entering the collected data • Introducing hospitals in precise coordinates and documenting them on the aerial image 3- Data analysis phase - The input data will be analyzed using Arc GIS tools, which will include spatial analysis and spatial query for any metadata as Use Arc GIS to produce different maps

- View data and results

- Assessing the problem of study

- Comparing that problem over the past years and the present

- Use ArcGIS tools to predict the magnitude of the problem over the coming years, if appropriate solutions are not developed and implemented
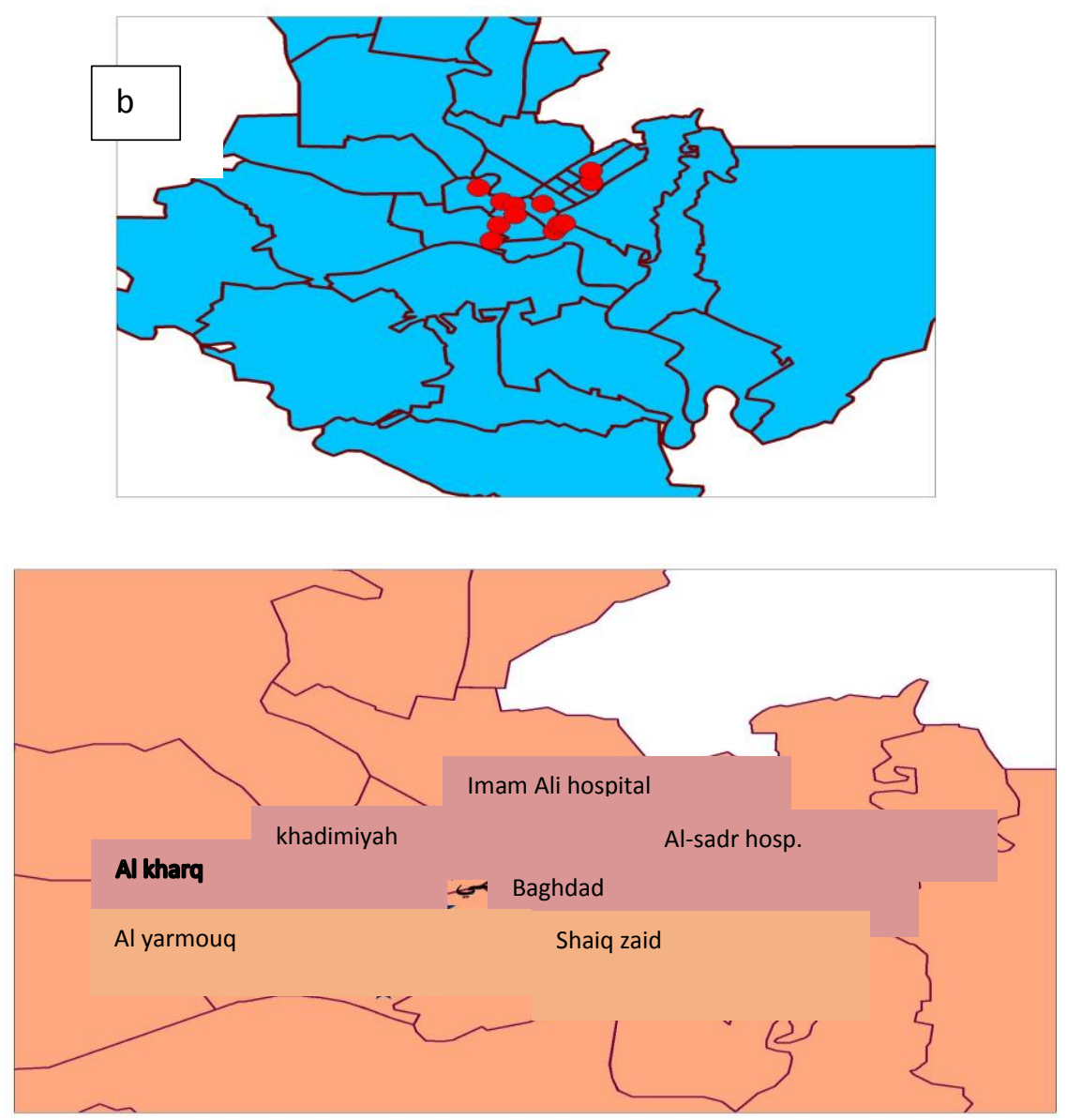

Figure (3): interpolation of Baghdad hospitals 


\section{Results}

Through our research, we have shown many benefits to the use of geographic information systems in different circumstances and times to achieve the objectives of both theoretical and practical studies, and can be listed as follows:

1. Ease of work and save time.

2. Precision and speed.

3. Possibility of updating, adding, deleting and renewing.

4. Objectivity, complete impartiality and full clarity.

5. The possibility of analysis and measurement of maps and the conduct of statistical aspects and processes. 6. Linking information between different sources.

7. Coverage and overlap with the use of maps, in the sense that can be placed a large number of maps placed on top of each other.

8. Forecasting and future forecasting.

Therefore, the idea of working in this area provides a lot of time and effort, organization and organization and the linking of information and analysis and future prospects to make full use of this subject.

\section{Recommendations}

1-increase the number of hospitals inside sadr city due to the apparent shortage in the number of hospitals compared to population density.

2-increase the number of hospitals inside kadhimiya due to the apparent shortage in the number of hospitals compared to population density

\section{References}

1. Anqari, Khalid (1989), Geographic Information Systems, Dammam Press, Saudi Arabia.

2. Aziz, Mohammed Al-Khuzama (2004), Geographic Information

3. d. Sameh Jazmati (2002), Geographic Information Systems, Dar Al-Sharq AlArabi, Beirut - Lebanon

4. Dr. Yacoub, Mohamed (2015), A Brief History of Geographic Information Systems, United Arab Emirates University Library.

5. El-Beltagy, Shawky, (1999), Advanced Geographic Information Systems, Dar Al-Thaqafa for Publishing and Distribution, Amman - Jordan.

6. Establishment for Printing and Publishing, Alexandria

7. Hamad, Sabah (2009), Geographic Information Systems, AlWarraq Publishing \& Distribution, Amman, Jordan

8. Jack, Beauville (2012), Application of GIS and Data Management, Harvard University Press, Cambridge

9. James, O'Brien (2002), Information Systems Management, translated by Nabil Maalouf, Dar Al Fikr Press, Beirut - Lebanon

10. Publications of the First Regional Conference (2002), "Geographical Information Systems and Regional Integration" Cairo 
11. Ramadan, Baqir Muhammad (1994), Framework for National Efforts Towards Geographic Information System in Saudi Arabia, Dissertation of the University of Pennsylvania

12. Ronald, Dick (2013), Practical Limits in GIS and Management of Stored Data and Methods of Achievement, Dar Alamein, Beirut, Lebanon.

13. Systems Basics and Applications of Geographers, Al-Ma'aref 